\title{
UV Mutagenesis as a Strategy to Enhance Growth and Lipid Productivity of Chlorella sp. 042
}

\author{
Rike Rachmayati*, Eva Agustriana1, Delicia Yunita Rahman ${ }^{1}$ \\ 1) Research Center for Biotechnology, Indonesian Institute of Sciences, Cibinong Science Center, Jl. Raya Bogor KM 46, 16911, \\ Indonesia
}

Submitted: 13 June 2020; Accepted: 22 October 2020; Published: 15 December 2020

\begin{abstract}
Microalgae appeared to be an alternative feedstock for renewable biodiesel production due to their capability to accumulate considerable amounts of lipids. In this study, mutagenesis using UVC light with different periods was applied to Chlorella sp. 042 to produce a microalgae strain with high lipid productivity of 45, 60, and 75 min. The Nile red fluorescence method was conducted to select a Chlorella sp. mutant with high neutral lipid and generated one mutant from every UV mutation period, M45-06, M60-02, and M75-21. All of the mutants have higher growth rates than the wild type. Chlorella sp. 042 M60-02 achieved the highest lipid productivity, with $34 \mathrm{mg} \mathrm{L}^{-1}$ day-1. Furthermore, as other major biochemical components, carbohydrate and protein contents were determined. Our results showed that all the mutants enhance their carbohydrate and protein contents compared to the wild type. However, mutations for more than 60 min do not intensely change the protein content of mutant microalgae. Gas chromatography-mass spectrophotometry analysis revealed that M60-02 mutant has similar FAME profiles with the wild type, which contain palmitic acid (C16:0), stearic acid (C 18:0), oleic acid (C18:1), and linoleic acid (C18:2). These results demonstrate that the UV mutation of Chlorella sp. 042 for $60 \mathrm{~min}$ is suitable as a source of biodiesel production.
\end{abstract}

Keywords: Biodiesel, Chlorella sp., Fatty acids, Lipid productivity, UV mutagenesis

\section{INTRODUCTION}

The limited availability of fossil energy sources and the negative impact of fossil fuels on the environment forced researchers to explore alternative and renewable energy sources capable of producing low carbon dioxide emissions (Tan et al., 2017). Biodiesel is a mono-alkyl ester with a longchain fatty acid, which is a derivative of animal fats or wastes cooking oil or vegetable oils (Yusuf \& Yaakub, 2010; Balat, 2011; Abbaszaadeh et al., 2012; Faried et al., 2017). The eminences of biodiesel compared to fossil fuels are its renewability, toxicfree, sulfur-free, and have better lubricity (Aransiola et al., 2014; Goh et al., 2019). However, these materials, especially those originating from vegetable oil, cause new problems due to their implications on food security and commodity prices (Goh et al., 2019). Besides, biodiesel production using crops as

\footnotetext{
*Corresponding author

Email: rikerachmayati24@gmail.com

(C) 2020, J. Tropical Biodiversity Biotechnology (CC BY-SA 4.0)
}

raw material requires extensive agricultural land and one of the causes of deforestation (Rawat et al., 2013).

Microalgae oil produced can be used as an alternative feedstock for biodiesel in terms of social and economic aspects. Microalgae are capable of accumulating oil with a shorter harvesting time and less volume of water demand and can be done in open land (Chen et al., 2018; Rawat et al., 2013). Oil productivity from algae is twenty times higher than oilseed plants based on a one-hectare area. Therefore, a more viable biodiesel feedstock (Chisti, 2007; Ahmad et al., 2011; Antoni et al., 2007; Feng et al., 2011; Rawat et al., 2013). Some microalgae with high lipid productivity have been identified as candidates for biodiesel production such as Chlamydomonas sp., Scenedesmus sp., Nannochloropsis oculata, Dunaliella salina, Botryococcus braunii, and Chlorella sp. (Chisti, 2007; Hosseini Tafreshi \& Shariati, 2009; Van Vooren et al., 2012; Yoo et al., 2010; Sarayloo et al., 2017). Nevertheless, biodiesel 
production from large-scale microalgae is still not economically feasible (Sarayloo et al., 2017). Therefore, it is important to find candidates for microalgae that have high lipid content with high biomass production (Zhang et al., 2010).

To obtain microalgae strain with high lipid content and biomass production, various strategies can be applied. Some of them include performing screening and species characterization of lipid producing microalgae (Vigeolas et al., 2012; Nascimento et al., 2013) followed by optimization of culture condition and cultivation techniques, and via metabolic engineering (Trentacoste et al., 2013) followed by the screening of lipid producing microorganism using lipophilic dye (Vigeolas et al., 2012). Screening and species characterization to derive robust strain require intensive effort, and many times, they fail to provide strain with high biomass and high lipid production. Meanwhile, metabolic engineering requires the elucidation of lipid metabolism processes and other related metabolism pathways as well as the knowledge about carbon flux in cellular processes (Trentacoste et al., 2013). Targeted genetic engineering is limited due to the lack of the genomic sequence and the detailed study about lipid-producing-microalgae that can be manipulated (Vigeolas et al., 2012).

In addition to those approaches, the effort to increase lipid production is also done via mutagenesis, either physically or chemically. This approach is simple and does not require genomic information as required in genetic engineering. Mutagenesis performed physically using UV irradiation is preferred to chemical mutagenesis. The former is considered more benign either for the operator or the environment, faster, and more effective (Fang et al., 2013; Sivaramakrishnan \& Incharoensakdi, 2017). UV mutagenesis has been applied to microalgae and other oleaginous microorganisms such as yeast to provide strain with improved lipid production (Tapia et al., 2012; Sharma et al., 2014; Liu et al., 2015; Sivaramakrishnan \& Incharoensakdi, 2017).

In this study, Cblorella vulgaris, either the mutagenized or wild type, is investigated for its lipid production as well as lipid productivity. This strain is acknowledged for its ability to grow in various conditions and its resistance to invaders (Pauline et al., 2006; Liang et al., 2009; Sarayloo et al., 2018). It also contains lipids mainly as triacylglycerol. Major fatty acids produced by $C$. vulgaris are saturated and monounsaturated fatty acids like palmitic acid, palmitoleic acid, stearic acid, and oleic acid, which are compatible to be employed as biodiesel feedstock (Yeh \& Chang, 2011; Sarkar \& Shimizu, 2015; Sarayloo et al., 2018). Besides, this species produces valuable metabolites such as protein, $\beta$ carotene, astaxanthin, as well as several types of polyunsaturated fatty acids (PUFAs) (Chacon-Lee \& Gonzalez-Marino, 2010; Singh \& Cu, 2010; Sarayloo et al., 2018).

Previous studies showed that applying mutagenesis to Chlorella sp. for 30 min increased its growth rate and lipid productivity to be 0.257 day $^{-1}$ and $11 \mathrm{mg} \mathrm{L}^{-1}$ day $^{-1}$ concerning wild type (growth rate was 0.196 day $^{-1}$ and lipid productivity was $9 \mathrm{mg}$ $\mathrm{L}^{-1}$ day $^{-1}$ ) (Rahman et al., 2020). In this study, we conducted UV mutagenesis to Chlorella sp. isolated from East Kalimantan River for 45, 60, and 75 min. We observed and determined the optimum period for UV mutagenesis concerning growth and lipid productivity. We also characterized fatty acid profiles of the mutants.

\section{MATERIALS AND METHODS}

\section{Microalgae strain and growth condition}

Wild type Chlorella sp. 042 was isolated from the Wain River, East Kalimantan, Indonesia. The cells were inoculated into $500 \mathrm{~mL}$ photobioreactors containing $400 \mathrm{~mL} \mathrm{AF6} \mathrm{medium} \mathrm{(140} \mathrm{mg} \mathrm{NaNO}_{3}$, $22 \mathrm{mg} \mathrm{NH}_{4} \mathrm{NO}_{3}, 30 \mathrm{mg} \mathrm{MgSO}_{4} .7 \mathrm{H}_{2} \mathrm{O}, 10 \mathrm{mg}$ $\mathrm{KH}_{2} \mathrm{PO}_{4}, 5 \mathrm{mg} \mathrm{K}_{2} \mathrm{HPO}_{5}, 10 \mathrm{mg} \mathrm{CaCl} 2.2 \mathrm{H}_{2} \mathrm{O}, 2 \mathrm{mg}$ Fe-Citrate, $2 \mathrm{mg}$ Citric acid, and 1,000 mL distilled water). The culture condition was maintained at 25 ${ }^{\circ} \mathrm{C}$ under continuous light $(800$ Lux $)$ with continuous aeration. The growth curves of the microalgae were made by daily measurement of optical density at $750 \mathrm{~nm}$ using a UV-Vis spectrophotometer (Shimadzu PharmaSpec UV1700).

\section{UV mutagenesis}

The mutagenized cell was conducted by $5 \mathrm{~mL}$ of Chlorella sp. 042 in the exponential growth phase. It was placed in the open petri dishes and exposed to the UV irradiation (Germicidal lamp, UVC $30 \mathrm{~W}$, Philips) at a distance of $25 \mathrm{~cm}$ for 45,60 , and 75 min. The mutagenized mutants were kept in the darkroom for $24 \mathrm{~h}$, to avoid light induction of cell recovery. The mutagenized cells were grown in AF6 agar medium and incubated under continuous light for 2-3 weeks in advance of single colonies appeared.

\section{Screening of mutants}

The single developed colonies on the agar plate were selected and transferred into a sterile 96-wells plate containing $200 \mu \mathrm{L}$ of AF6 medium. Plates were incubated under constant light with agitation at 150 rpm for 7 days. Cell densities of each culture were measured using Varioscan ${ }^{\mathrm{TM}}$ LUX multimode 
microplate reader (Thermo Fisher Scientific). The amount of neutral lipid was determined using modified Chen et al. (2009) methods by following Nile Red fluorescence in cell suspensions diluted to the concentration of approximately 0.1 at $750 \mathrm{~nm}$.

\section{Determination of cell dry weight and lipid} content

The cell dry weight of Chlorella sp. 042 was determined gravimetrically. Aliquot of $10 \mathrm{~mL}$ culture was transferred to a $15 \mathrm{~mL}$ falcon tube of a known mass and centrifuged at $8000 \mathrm{rpm}$ for $10 \mathrm{~min}$. The supernatant was discharged, and the remaining cell pellets were dried at $60{ }^{\circ} \mathrm{C}$ for $24 \mathrm{~h}$. The dry weight of cell pellets was determined gravimetrically (Rahman et al., 2020).

Total lipid content was determined by performing lipid extraction prior to gravimetric analysis. Lipid was extracted according to Ryckebosch et al. (2012) with modification. A solution of chloroform and methanol $(1: 1, \mathrm{v} / \mathrm{v})$ was added to the lyophilized cell pellet and mixed. Water was added to the homogenized mixture until the final concentration of chloroform-methanol-water of 2:2:1 (v/v) was reached. The upper layer (lipid) was separated by centrifugation $(8000 \mathrm{rpm}, 10 \mathrm{~min}$ ) and evaporated at room temperature. The dried lipid layer was then determined gravimetrically (Ryckebosch et al., 2012).

\section{FAME analysis}

Transesterification of microalgae lipids was performed before analysis using GC-MS. Derivatization of lipid into its methyl ester was done according to Lewis et al. (2000), with modification. Reagent, consisting of methanol: chloroform: chloric acid (10:1:1), was added to a lyophilized microalga cell, into duplicate, screw-capped reaction tubes. The tubes were mixed using vortex and heated at $90{ }^{\circ} \mathrm{C}$ for $2 \mathrm{~h}$ in a water bath. After the reaction was completed, the reaction mixtures were set to cool until it reached $25 \pm 2{ }^{\circ} \mathrm{C}$ and to which the water was added and mixed. To each reaction mixture, hexane was added, mixed, and was left alone until it reached phase separation. The hexane addition step was repeated twice, and the upper layer (organic phase) was being collected and subjected to GC-MS analysis. This step was done for both mutant and wild type lipids.

FAME analysis using GC-MS (Shimadzu QP 2010 Ultra, DB-23 column) was performed qualitatively. The oven temperature was $50{ }^{\circ} \mathrm{C}$ for 1 min and increased at $25{ }^{\circ} \mathrm{C} \mathrm{min}-1$ up to $180{ }^{\circ} \mathrm{C}$ for 4 min. An increment of $5{ }^{\circ} \mathrm{C} \mathrm{min}^{-1}$ followed the step until $235{ }^{\circ} \mathrm{C}$ for $5 \mathrm{~min}$. The temperature of the ion source was set to $230{ }^{\circ} \mathrm{C}$, with an interface temperature of $250{ }^{\circ} \mathrm{C}$ and the solvent cut time of 2 min. The peaks derived from GC-MS analysis were assigned according to the reference of FAME mix C14-C22 components.

\section{Determination of Carbohydrate and Protein}

Carbohydrate determination was held using the phenol-sulfuric acid method, according to Dubois et al. (1956), with modification. Wet biomass was incubated with $2.25 \%$ sulfuric acid at $90{ }^{\circ} \mathrm{C}$ for 70 min. The sugar solution $(0.5 \mathrm{~mL})$ was pipetted to the reaction tube. $5 \%$ phenol and $96 \%$ sulfuric acid were mixed with the sugar solution. The absorbance of the mixed solution was measured using a UV-Vis spectrophotometer at $490 \mathrm{~nm}$.

The determination of protein content was done using the dye-binding assay (Bradford, 1976). Phosphate buffer ( $\mathrm{pH}$ 7) was added to microalgae wet biomass. The cell was then disrupted using sonication for $15 \mathrm{~s}$ and repeated until 10 cycles. Bradford reagent was added to $0.3 \mathrm{~mL}$ of supernatant. The solution was determined using the $\mathrm{UV}$-Vis spectrophotometer at $595 \mathrm{~nm}$.

\section{Statistical Analysis}

To determine the significant difference among groups $(P<0,05)$, all average values of mutants were analyzed against the control employing one way ANOVA and t-test analysis by using Microsoft Excel Software.

\section{RESULTS AND DISCUSSION}

\section{Screening of mutants}

Mutagenized green microalgae, Chlorella vulgaris, were screened for its lipid content using the Nile red method. Nile red dye has been applied to detect neutral lipid in various oleaginous microorganisms including yeasts (Sitepu et al., 2014; Rostron et al., 2015), bacteria (Alves et al., 2017), and microalgae (Chen et al., 2009; Huang et al., 2009; Satpati \& Pal, 2014). This hydrophobic benzophenoxazone dye emits fluorescence as it contacts lipid bodies and organic solvents (Halim \& Webley, 2015). Such a characteristic makes it useful to be applied in lipid staining to detect lipid content. In this study, DMSO was used as a carrier for the Nile red dye. The use of DMSO as well as other cell pre-treatments such as cell grounding in liquid nitrogen and the use of methanol, acetone, and ethanol as a solvent were proved to increase fluorescent intensity compared to those without pre-treatment (Chen et al., 2009). The pre-treatments applied to make it possible for the Nile red method to be applied to stain and detect lipid content in green algae are known to have thick and rigid cell walls (Chen et al., 2009). The use of this 
Nile Red method also enables high throughput screening, which is difficult to achieve when applied by the conventional gravimetric method. According to fluorescence intensity measured for 48 colonies, generated from 45, 60, and 75 min UV radiation (Figure 1), three colonies showed prominent results, indicating high lipid content. The three colonies are M45-06, M60-02, and M75-21, which originated from 45, 60, and 75 min radiation, respectively. The three colonies were considered as potential candidates for lipid production and subjected to further analysis.

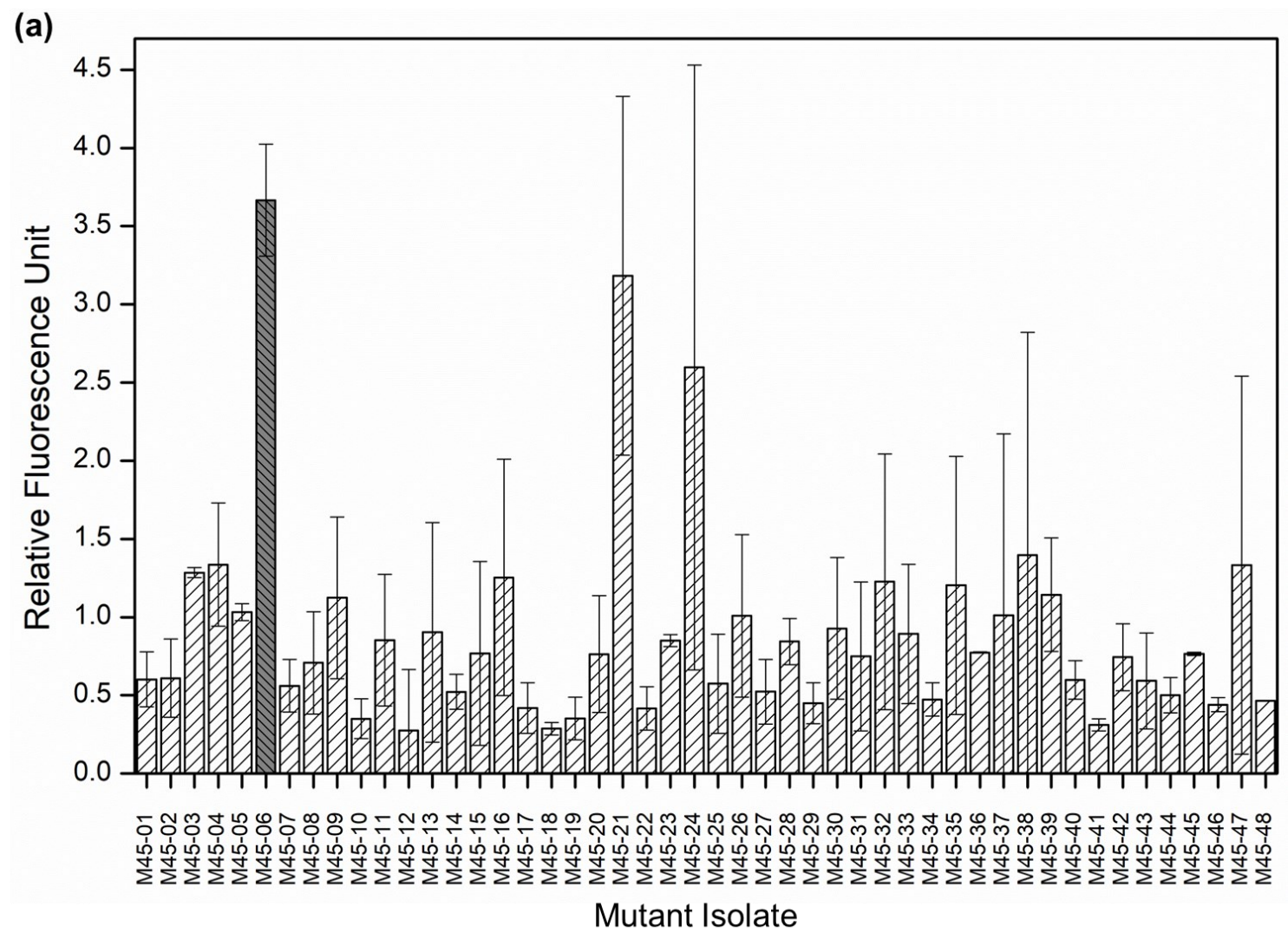

(b)

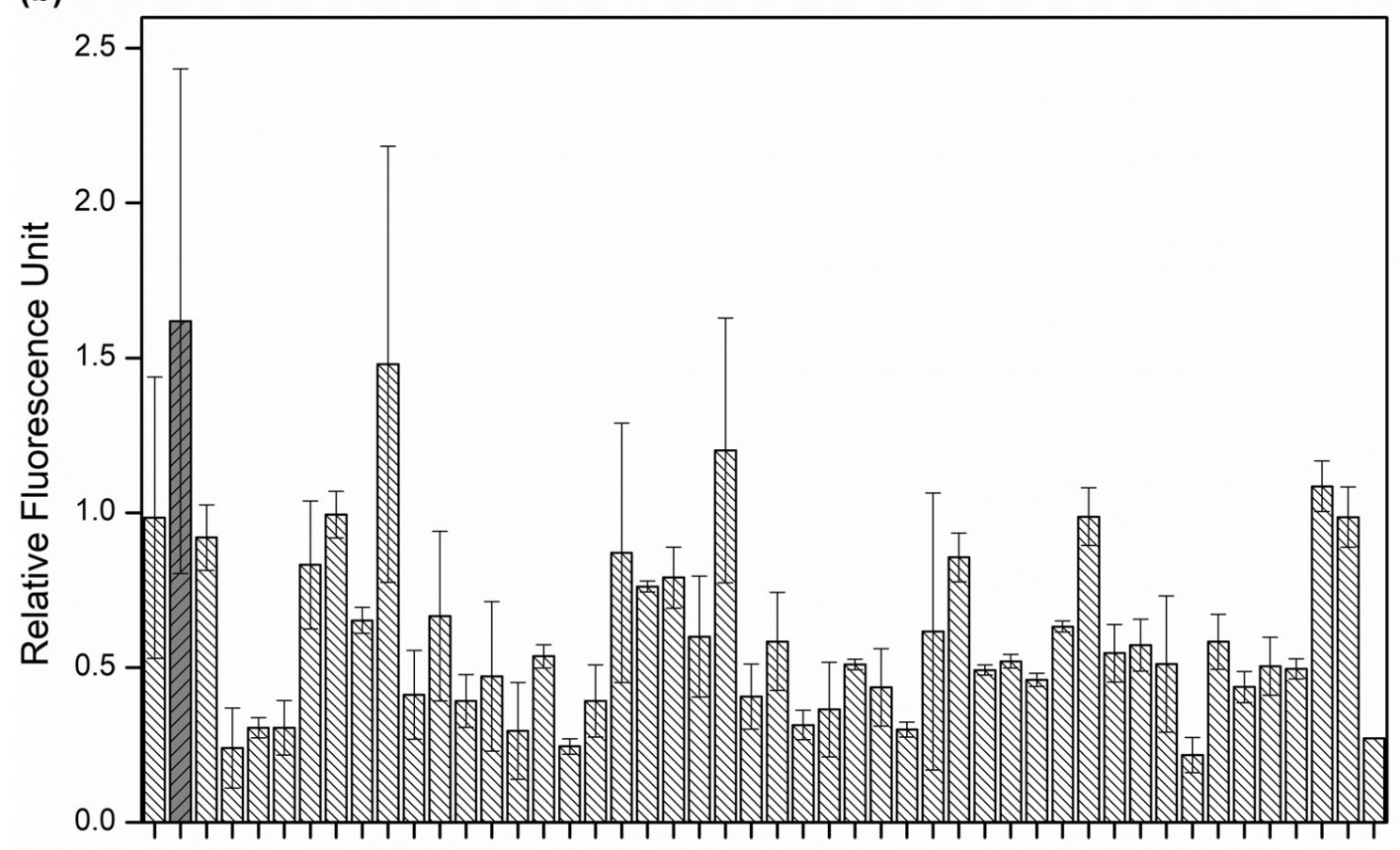

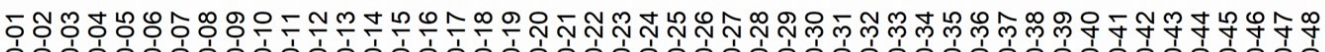

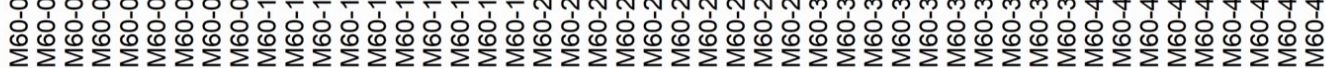






Figure 1. Relative amounts of lipids in Chlorella sp. 042 after UV mutagenesis: (a). M45-06 mutant; (b) M60-02 mutant; and (c) M75-21 mutant.

\section{Cell dry weight and lipid contents}

The growth rate of Chlorella sp. 042 was measured daily using a UV-Vis spectrophotometer. Both wild type and mutants showed an increase in growth rate until the last day of cultivation (Figure 2). The wild type achieved a growth rate of $0.503 \mathrm{day}^{-1}$, while all mutants exhibited a higher growth rate with 0.641, 0.783, and 0.7369 day-1 for M45-06, M60-02, and M75-22, respectively. The mutant M60-02 showed the highest growth rate of all. Previous studies showed that UV mutagenesis to the Chlorella sp. increased the biomass productivity and the lipid content, and thus, this strategy suitable for biodiesel production (Liu et al., 2015; Sivaramakrishnan et al., 2017). Our study found a similar result in which all of the mutants have higher biomass productivity $(P<0.05)$ than the wild type $\left(29.95 \mathrm{mg} \mathrm{L}^{-1}\right.$ day $\left.{ }^{-1}\right)$. The M60-02 mutant achieved the highest biomass productivity $(P<0.05)$ with a value of $61.8 \mathrm{mg} \mathrm{L}^{-1}$ day ${ }^{-1}$. The biomass productivity achieved was also in line with the growth rate in which the mutant M6002 with the highest biomass productivity also showed the highest growth rate, which increased by two-fold concerning the wild type. The biomass productivity, lipid content, and lipid productivity of Chlorella sp. 042 wild type and mutants are provided in Table 1.

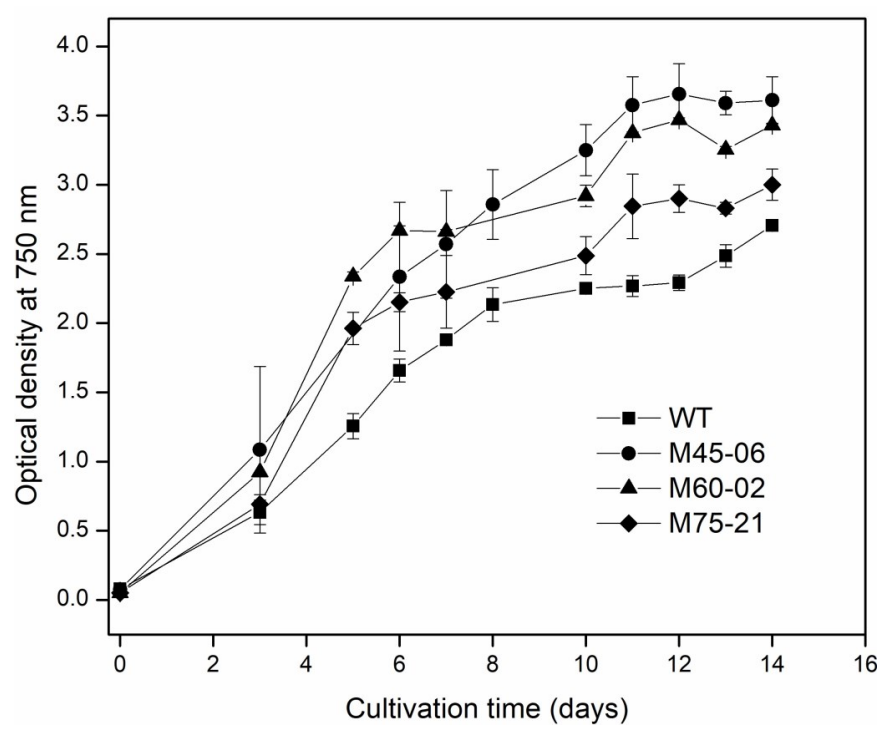

Figure 2. Growth curve of Chlorella sp. 042 wild type and mutants.

The lipid content of M45-06, M60-02, and M75-21 showed higher value $(P<0.05)$ than wild type $(30.8 \%), 60.5 \%, 55 \%$, and $40.6 \%$, respectively. The lipid content of M60-02 and M7521 were lower than those of M45-06 (Table 1). However, the biomass productivity of the latter was lower than other mutants. Occasionally, microalgae with a high growth rate have low lipid content, whilst microalgae with a low growth rate have high lipid content (Liu et al., 2015). In microalgae, there 
Table 1. Lipid content, biomass productivity, and lipid productivity of Chlorella sp. 042 wild type and mutants.
Strain
Lipid Content*
$(\%)$
Biomass Productivity*
$\left(\mathrm{mg} \mathrm{L}^{-1}\right.$ day $\left.^{-1}\right)$
Lipid Productivity*
$\left(\mathrm{mg} \mathrm{L}^{-1}\right.$ day $\left.^{-1}\right)$

\begin{tabular}{llll}
\hline WT & $30.8 \pm 1.44^{\mathrm{a}}$ & $29.95 \pm 1.77^{\mathrm{a}}$ & $9.34 \pm 0.97^{\mathrm{a}}$ \\
M45-06 & $60.5 \pm 3.8^{\mathrm{b}}$ & $50.7 \pm 9.92^{\mathrm{b}}$ & $27.2 \pm 0.6^{\mathrm{b}}$ \\
M60-02 & $55.1 \pm 7.2^{\mathrm{c}}$ & $61.8 \pm 3.5^{\mathrm{c}}$ & $34.0 \pm 1.9^{\mathrm{c}}$ \\
M75-21 & $40.6 \pm 4.4^{\mathrm{d}}$ & $51.1 \pm 0.5^{\mathrm{d}}$ & $20.7 \pm 0.2^{\mathrm{d}}$ \\
\hline
\end{tabular}

are three steps responsible for lipid biosynthesis, including fatty acid synthesis, acyl chain prolongation, and lipid formation. Acetyl-CoA carboxylase (ACC) is one of the essential enzymes in fatty acid synthesis. This enzyme catalyzes the biotin -dependent carboxylation of acetyl-CoA to form malonyl-CoA, which is considered a step-in fatty acid synthesis (Sendl et al., 1992; Li \& Cronan, 1993; Kim, 1997; Davis et al., 2000; Courchesne et al., 2009). Exposure of UV irradiation to the microalgae may affect the ACC and nutrient fixation. Thus, enhancing the lipids content. High lipid content in UV-mutagenized-Chlorella sp. was observed to have higher ACC concentrations than those of the untreated Chlorella sp. (Liu et al., 2015).

As shown in Table 1, the lipid productivity for UV mutation microalgae was higher than the value for the wild type $\left(9 \mathrm{mg} \mathrm{L}{ }^{-1} \mathrm{day}^{-1}\right)(P<0.05)$. Mutant M60-02 has the highest value of lipid productivity of $34 \mathrm{mg} \mathrm{L}^{-1} \mathrm{day}^{-1}(P<0.05)$. The total lipid production is proportional to the biomass productivity and the lipid content, which is a significant parameter for large-scale lipid production of microalgae (Fan et al., 2014). Lipid productivity is also a determining factor for the cost-effective production of biodiesel (Rahman et al., 2020). The results suggest that the UV irradiation strategy for $60 \mathrm{~min}$ can result in the

(a) 60



most favorable lipid productivity (Table 1).

\section{Carbohydrate and protein contents}

The major biochemical component of microalgae consisted of proteins, carbohydrates, and lipids, and their composition depends on the strain and culture condition (Behrens \& Kyle, 1996; Vigeolas et al., 2012). Since we perform UV mutagenesis, which can alter the metabolism of microalgae, the carbohydrates and protein assay are required to know the effect of the mutation on those compounds. Our study found that the M60-02 and M75-21 $(P<0.05)$ carbohydrates and protein content were higher than those of the wild type after 14 days of cultivation. The results are shown in Figure 3, the carbohydrates content increased along with period times of mutation M60-02, and M75-21 which contained $38 \%$ and $40 \%$, respectively. The carbohydrate content of M45-06 (34.5 $\pm 20 \%)$ was not significantly different compared to the wild type $(24 \pm 0.39 \%)$. The M60-02 and M75-21 mutants showed higher protein content compared to the wild type $(4.55 \pm 0.2 \%)$. However, the M60-02 and M7521 mutants exhibited similar results $(P>0.05), 6.76 \%$ $\pm 0.04 \%$ and $6.93 \pm 0.16 \%$, respectively. Further study at the genome level needs to be performed to identify the underlying biochemical process affected

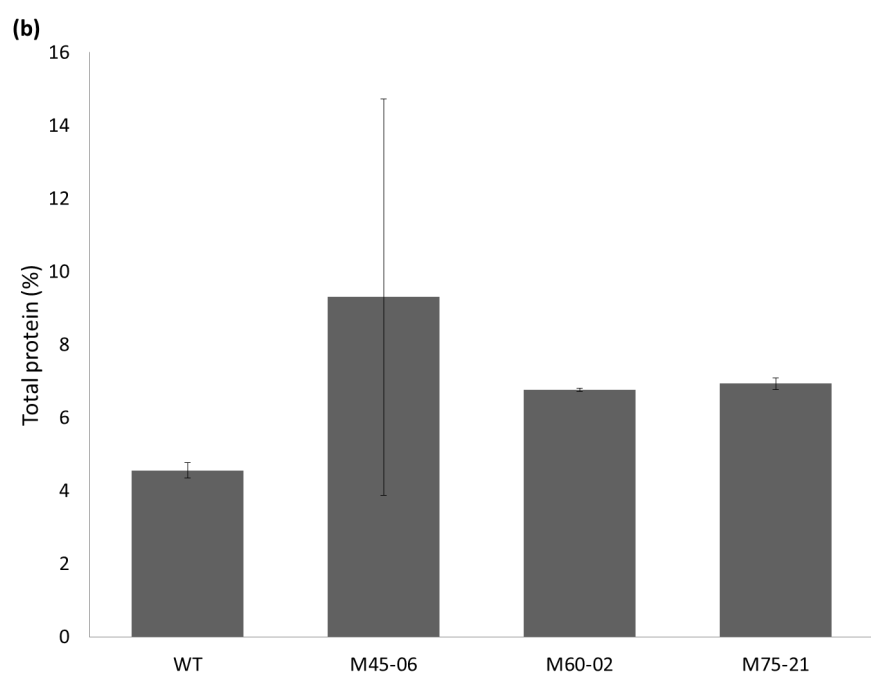

Figure 3. Primary metabolites content of Chlorella sp. 042 wild type and mutants: (a) carbohydrate and (b) protein. 
by UV mutagenesis.

Fatty acid profiles of mutagenized microalgae The fatty acid contents of lipids from both mutants and wild type can be inferred by the FAMEs detected by GC-MS analysis. The fatty acids contained in lipids determine the properties of biodiesel (Knothe, 2009). In this study, the analysis performed qualitatively and gave insight into the lipid's fatty acid profile and whether the mutagenesis affects the fatty acid profile of the strain. The result obtained in this study showed that the fatty acid contained in the lipids of both mutant and wild type are similar, with minor differences in which we did not observe oleic acid (C 18:1) in M45-06 and linoleic acid (C18:2) in M75-21. The same result was also shown by the study performed by Vigeolas et al. (2012) on Cblorella sorokiniana and Scenedesmus obliquus. In that study, both mutants and wild type strains produced the same type of fatty acids. However, the composition of certain fatty acids varies in mutant and wild type.

The content of lipid from both strains (Table 2) consists of saturated fatty acid, palmitic acid (C16:0) accompanied by stearic acid (C18:0), and unsaturated fatty acid components, oleic and linoleic acid. The result resembled the fatty acids profile of immobilized C. vulgaris obtained in Abu Sepian et al. (2017). Lipid from C. vulgaris was mainly composed of saturated fatty acids $(60 \%)$, consisting of palmitic and stearic acid, and the remaining portion (40\%) was comprised of unsaturated fatty acid, consisted of oleic, linoleic, and linolenic acid (Abu Sepian et al., 2017). The more significant proportion of saturated fatty acids will contribute to the higher cetane number of the fuel. More specifically, the chain length and degree of unsaturation will affect the cetane number (Knothe, 2010). The higher the cetane number, the shorter the ignition delay time, which is one of the desired properties of a fuel (Knothe, 2009). The presence of palmitic and stearic acid thus may contribute to biodiesel with the desired property. However, further analysis is required to determine the exact composition of each fatty acid. Besides, the FAMEs derived from transesterification are also required to fulfil several other criteria like viscosity, cold flow, oxidative stability, and lubricity as determined in a certain standard of biodiesel (e.g., ASTM D6751, EN 14214) to be eligible for use and commercialization (Knothe, 2009).

\section{CONCLUSION}

Based on Nile red fluorescence assay, we found three microalgae mutants from three periods of mutation time, $45 \mathrm{~min}, 60 \mathrm{~min}$, and $75 \mathrm{~min}$, and there are M45-06, M60-02, and M75-21, respectively. The growth rate for all mutants is higher than the wild type after 14 days of cultivation, so does the lipid productivity. The M60-02 mutant achieved the highest lipid productivity, with $34 \mathrm{mg} \mathrm{L}^{-1}$ day-1. Surprisingly, carbohydrate and protein contents of the mutants (M60-02 and M75-21) are also higher than the wild type. We found no difference in FAMEs profile of M60-02 mutant and the wild type that included palmitic acid, stearic acid, oleic acid, and linoleic acid. Finally, our results indicate that random mutation by UV mutagenesis for $60 \mathrm{~min}$ is suggested as the best way for generating microalgae mutant with higher growth rate and lipid productivity for environmentally friendly and sustainable energy sources such as biodiesel.

\section{ACKNOWLEDGMENTS}

Authors gratefully acknowledge DIPA grant 2019 of Research Center for Biotechnology, Indonesian Institute of Sciences. We also thank Mr. Khairul Anam and Mr. Swastika Praharyawan for their guidance in statistical analysis.

\section{REFERENCES}

Abbaszaadeh, A., Ghobadian, B., Omidkhah, M. R. and Najafi, G., 2012, Current biodiesel production technologies: a comparative review, Energy Conversion and Management 63, 138-148.

Table 2. Fatty Acid Methyl Ester (FAMEs) profile of wild type and mutant.

Strains

FAMEs

WT

M45-06

M60-02

M75-21

\begin{tabular}{|c|c|c|c|c|}
\hline C16:0 & $\mathbf{V}$ & $\mathbf{V}$ & $\mathbf{V}$ & $\mathbf{V}$ \\
\hline C18:0 & $\mathbf{V}$ & $\mathbf{V}$ & $\mathbf{V}$ & $\mathbf{V}$ \\
\hline C18:1 & $\mathbf{V}$ & - & $\mathbf{V}$ & $\mathbf{V}$ \\
\hline C18:2 & $\mathbf{V}$ & $\mathbf{V}$ & $\mathbf{V}$ & - \\
\hline
\end{tabular}


Abu Sepian, N. R., Mat Yasin, N. H., Zainol, N., Rushan, N.H. and Ahmad, A.L., 2017, Fatty acid profile from immobilised Chlorella vulgaris cells in different matrices, Environmental Technology 40(9), 1110-1117.

Ahmad, A. L., Yasin, N. H. M., Derek, C. J. C. and Lim, J. K., 2011, Microalgae as a sustainable energy source for biodiesel production: a review. Renewable and Sustainable Energy Reviews 15, 584-593.

Alves, L. P. S., Almeida, A.T., Cruz, L.M., Pedrosa, F.O., de Souza, E.M., Cubatsu, L.S., MüllerSantos, M. and Valdameri, G., 2017, A simple and efficient method for poly-3hydroxybutyrate quantification in diazotrophic bacteria within 5 minutes using flow cytometry, Brazilian Journal of Medical and Biological Research 50(1), 1-10.

Aransiola, E. F., Ojumu, T. V., Oyekola, O. O., Madzimbamuto, T. F. \& Ikhu-Omoregbe, D. I. O., 2014, A review of current technology for biodiesel production: state of the art, Biomass and Bioenergy 61, 276-297.

Balat, M., 2011, Potential alternatives to edible oils for biodiesel production-a review of current work, Energy Conversion and Management 52(2), 1479-1492.

Behrens, P. W. \& Kyle, D. J., 1996, Microalgae as a source of fatty acids, Journal of Food Lipids 3, 259-272.

Bradford, M. M., 1976, A rapid and sensitive method for the quantitation of microgram quantities of protein utilizing the principle of protein-dye binding, Analytical Biochemistry 72, 248-254.

Chen, W., Zhang, C., Song, L., Sommerfeld, M. and $\mathrm{Hu}$, Q., 2009, A high throughput Nile red method for quantitative measurement of neutral lipids in microalgae, Journal of Microbiological Methods 77, 41-47.

Chen, J., Li, J., Dong, W., Zhang, X., Tyagi, R. D., Drogul, P. and Surampalli, R. Y., 2018, The potential of microalgae in biodiesel production, Renewable and Sustainable Energy Reviews 90, 336-346.

Chisti, Y., 2007, Biodiesel from microalgae, Biotechnology Advances 25, 294-306.

Courchesne, N. M. D., Parisien, A., Wang, B. and Lan, C. Q., 2009, Enhancement of lipid production using biochemical, genetic and transcription factor engineering approaches, Journal of Biotechnology 14(1), 31-41.

Davis, M. S., Solbiati, J. and Cronan, Jr. J. E., 2000, Overproduction of acetyl-CoA carboxylase activity increases the rate of fatty acid biosynthesis in Escherichia coli, Journal of Biological Chemistry 275(37), 28593-28598.
Dubois, M., Gilles, K. A., Hamilton, J. K., Rebers, P. A. \& Smith, F., 1956, Colorimetric method for determination of sugars and related substances, Analytical Chemistry 28(3), 350-356.

Fan, J., Cui, Y., Wan, M., Wang, W. \& Li, Y., 2014, Lipid accumulation and biosynthesis genes response of the oleaginous Chlorella pyrenoidosa under three nutrition stressors, Biotechnology for Biofuels 7(17).

Fang, M., Jin, L., Zhang, C., Tan, Y., Jiang, P., Ge, N., Li, H. \& Xing, X., 2013, Rapid mutation of Spirulina platensis by a new mutagenesis system of atmospheric and room temperature plasmas (ARTP) and generation of a mutant library with diverse phenotypes, PLoS ONE 8(10), 112.

Faried, M., Samer, M., Abdelsalam, E., Yousef, R. S., Attia, Y. A. \& Ali, A. S., 2017, Biodiesel production from microalgae: Processes, technologies and recent advancements, Renewable and Sustainable Energy Reviews 79, 893 913.

Feng, Y., Li C. \& Zhang, D., 2011, Lipid production of Chlorella vulgaris cultured in artificial wastewater medium, Bioresource Technology 102 (1), 969-975.

Goh, B. H. H., Ong, H. C., Cheah, M. Y., Chen, W., Yu, K. L. \& Mahlia, T. M. I., 2019, Sustainability of direct biodiesel synthesis from microalgae biomass: A critical review, Renewable and Sustainable Energy Reviews 107, 5974.

Halim, R. \& Webley, P. A., 2015, Nile Red Staining for Oil Determination in Microalgal Cells: A New Insight through Statistical Modelling, International Journal of Chemical Engineering.

Huang, G. H., Chen, G. \& Chen, F., 2009, Rapid screening method for lipid production in alga based on Nile red fluorescence, Biomass and Bioenergy 33(10), 1386-1392.

Hosseini Tafreshi, A. \& Shariari, M., 2009, Dunaliella biotechnology: methods and applications, Journal of Applied Microbiology 107(1), 14-35.

Kim, K. H., 1997, Regulation of mammalian acetylcoenzyme A carboxylase, Annual Review of Nutrition, 77-99.

Knothe, G., 2009, Improving biodiesel fuel properties by modifying fatty ester composition, Energy and Environmental Science 2 (7), 759-766.

Knothe, G., 2010, Biodiesel and renewable diesel: A comparison, Progress in Energy and Combustion Science 36(3), 364-373. 
Li, S. J. \& Cronan, Jr. J. E., 1993, Growth rate regulation of Escherichia coli acetyl coenzyme A carboxylase, which catalyzes the first committed step of lipid biosynthesis, Journal of Bacteriology 175(2), 332-340.

Liu, S., Zhao, Y., Liu, L., Ao, X., Ma, L., Wu, M. \& Ma, F., 2015, Improving cell growth and lipid accumulation in green microalgae Chlorella sp. via UV irradiation, Applied Biochemistry and Biotechnology 175, 3507-3518.

Nascimento, I. A., Marquez, S.S.I., Cabanelas, I.T.D., Pereira, S.A., Druzian, J.I., de Souza, C.O., Vich, D.V., de Carvalho, G.C. \& Nascimento, M.A., 2013, Screening microalgae strains for biodiesel production: Lipid productivity and estimation of fuel quality based on fatty acids profiles as selective criteria, Bioenergy Research 6(1), 1-13.

Rahman D Y., Rachmayati R., Widyaningrum D. N. \& Susilaningsih D., 2020, Enhancement of lipid production of Chlorella sp. 042 by mutagenesis, IOP Conference Series: Earth and Environmental Sciences (EES) 439, 1-6.

Rawat, I., Ranjith Kumar, R., Mutanda, T. \& Bux, F., 2013, Biodiesel from microalgae: A critical evaluation from laboratory to large scale production, Applied Energy 103, 444-467.

Rostron, K. A., Rolph, C. E. \& Lawrence, C. L., 2015, Nile red fluorescence screening facilitating neutral lipid phenotype determination in budding yeast, Saccharomyces cerevisiae, and the fission yeast Schizosaccharomyces pombe, Antonie van Leeuwenhoek, International Journal of General and Molecular Microbiology 108 (1), 97-106.

Ryckebosch, E., Muylaert, K. \& Foubert, I., 2012, Optimization of an analytical procedure for extraction of lipids from microalgae, Journal of the American Oil Chemists's Sociecty' 89, 189-198.

Sarayloo, E., Tardu, M., Unlu, Y. S., Simsek, S., Cehavir, G., Erkey, C. \& Kavakli, I. H., 2017, Understanding lipid metabolism in high-lipidproducing Chlorella vulgaris mutants at the genome-wide level, Algal Research 28, 244252.

Sarayloo, E., Simsek, S., Unlu, Y. S., Cevahir, G., Erkey, C. \& Kavakli, I. H., 2018, Enhancement of the lipid productivity and fatty acid methyl ester profile of Chlorella vulgaris by two rounds of mutagenesis, Bioresource Technology 250, 764-769.

Satpati, G. G. \& Pal, R., 2014, Rapid detection of neutral lipid in green microalgae by flow cytometry in combination with Nile red staining an improved technique, Annals of Microbiology 65(2), 937-949.
Sendl, A., Schliack, M., Loser, R., Stanislaus, F. \& Wagner, H., 1992, Inhibition of cholesterol synthesis in vitro by extracts and isolated compounds prepared from garlic and wild garlic, Atherosclerosis 94(1), 79-85.

Sharma, K., Li, Y. \& Schenk, P. M., 2014, UV-Cmediated lipid induction and settling, a step change towards economical microalgal biodiesel production, Green Chemistry, 16(7), 3539-3548.

Sitepu, I. R., Jin, M., Fernandez, J.E., da Costa Sousa, L., Balan, V. \& Boundy-Mills, K.L., 2014, Identification of oleaginous yeast strains able to accumulate high intracellular lipids when cultivated in alkaline pretreated corn stover, Applied Microbiology and Biotechnology 98 (17), 7645-7657.

Sivaramakrishnan, R. \& Incharoensakdi, A., 2017, Enhancement of lipid production in Scenedesmus sp. by UV mutagenesis and hydrogen peroxide treatment, Bioresource Technology 235, 366-370.

Tan, X., Uemura, Y., Lim, J. W., Wong, C. Y. \& Lee, K. T., 2017, Cultivation of microalgae for biodiesel production: A review on upstream and downstream processing, Chinese Journal of Chemical Engineering 26(1), 17-30.

Tapia, E. V., Anschau, A., Coradini, A.LV., Franco, T.T. \& Deckmann, A.C., 2012, Optimization of lipid production by the oleaginous yeast Lipomyces starkeyi by random mutagenesis coupled to cerulenin screening, $A M B$ Express 2 (64), 1-8.

Trentacoste, E. M., Shrestha, R.P., Smith, S.R., Gle, C., Hartmann, A.C., Hildebrand, M. \& Gerwick, W.H., 2013, Metabolic engineering of lipid catabolism increases microalgal lipid accumulation without compromising growth, Proceedings of the National Academy of Sciences of the United States of America 110(49), 19748-19753.

Van Vooren, G., Le Grand, F., Legrand, J., Cuine, S., Peltier, G. \& Pruvost, J., 2012, Investigation of fatty acids accumulation in Nannocbloropsis oculata for biodiesel application, Bioresource Technology 124, 421-432.

Vigeolas, H., Duby, F., Kaymak, E., Niessen, G., Motte, P., Franck, F. \& Remacle, C., 2012, Isolation and partial characterization of mutants with elevated lipid content in Chlorella sorokiniana and Scenedesmus obliquus, Journal of Biotechnology 162, 3-12.

Yoo C., Jun S. Y., Lee J. Y. Ahn C. Y. \& Oh H. M., 2010, Selection of microalgae for lipid production under high levels carbon dioxide, Bioresource Technology, 101(Suppl 1), pp. S71S74. 
Yusuf, N. N. A. N., Kamarudin, S. K. \& Yaakub, Z., 2010, Overview on the current trends in biodiesel production, Energy Conversion and Management 52, 2741-2751.
Zhang, X. Z., Hu, Q., Sommerfeld, M., Puruhito, E. \& Chen, Y.S., 2010, Harvesting algal biomass for biofuels using ultrafiltration membranes, Bioresource Technology 101, 5297-5304. 